\title{
Chinese herbal medicine formula Gu-Ben-Fang-Xiao-Tang attenuates airway inflammation by modulating Th17/Treg balance in an ovalbumin-induced murine asthma model
}

\author{
GUIYING RUAN ${ }^{1 *}$, BAOHONG TAO ${ }^{2 *}$, DONGGUO WANG ${ }^{3 *}$, YONG LI $^{2}$, JINGYI WU $^{4}$ and GENQUAN YIN ${ }^{1}$ \\ Departments of ${ }^{1}$ Paediatrics and ${ }^{2}$ Otorhinolaryngology; ${ }^{3}$ Central Laboratory; ${ }^{4}$ Department of Traditional Chinese Medicine, \\ Taizhou Municipal Hospital, Medical College of Taizhou University, Taizhou, Zhejiang 318000, P.R. China
}

Received June 4, 2015; Accepted May 25, 2016

DOI: $10.3892 / \mathrm{etm} .2016 .3507$

\begin{abstract}
Gu-Ben-Fang-Xiao-Tang (GBFXT) is a traditional Chinese medicine formula consisting of 11 medicinal plants, which has been used in the treatment of asthma. The present study aimed to determine the protective effects and the underlying mechanisms of GBFXT on ovalbumin (OVA)-induced allergic inflammation in a mouse model of allergic asthma. A total of 50 mice were randomly assigned to the following five experimental groups: Normal, model, montelukast $(2.6 \mathrm{mg} / \mathrm{kg})$, $12 \mathrm{~g} / \mathrm{kg}$ GBFXT and $36 \mathrm{~g} / \mathrm{kg}$ GBFXT groups. Airway responsiveness was measured using the forced oscillation technique, while differential cell count in the bronchoalveolar lavage fluid (BALF) was measured by Wright-Giemsa staining. Histological assessment was performed by hematoxylin and eosin staining, while BALF levels of Th17/Treg cytokines were measured by enzyme-linked immunosorbent assay, and the proportions of Th17 and Treg cells were evaluated by flow cytometry. The results showed that GBFXT suppressed airway hyperresponsiveness during methacholine-induced constriction, reduced the percentage of leukocytes and eosinophils, and resulted in decreased absolute neutrophil infiltration in lung tissue. In addition, GBFXT treatment significantly decreased the IL-17A cytokine level and increased the IL-10 cytokine level in the BALF. Furthermore, GBFXT significantly suppressed Th17
\end{abstract}

Correspondence to: Professor Baohong Tao, Department of Otorhinolaryngology, Taizhou Municipal Hospital, Medical College of Taizhou University, 381 Zhongshan East Road, Taizhou, Zhejiang 318000, P.R. China

E-mail: tbhong1966@qq.com

Professor Dongguo Wang, Central Laboratory, Taizhou Municipal Hospital, Medical College of Taizhou University, 381 Zhongshan East Road, Taizhou, Zhejiang 318000, P.R. China E-mail: wdgtzs@163.com

*Contributed equally

Key words: Gu-Ben-Fang-Xiao-Tang, Treg/Th17 balance, airway inflammation, asthma cells and increased Treg cells in asthmatic mice. In conclusion, the current results demonstrated that GBFXT may effectively inhibit the progression of airway inflammation in allergic asthma, partially by modulating the Th17/Treg cell balance.

\section{Introduction}

Allergic asthma is a chronic respiratory disease that is characterized by obstruction of airflow as a response to certain triggers, airway hyperresponsiveness and increased airway inflammation. The chronic inflammation is associated with airway hyperresponsiveness resulting in recurrent episodes of coughing, chest tightness, breathlessness and wheezing, particularly in the early morning or at night (1). Allergic asthma has become one of the most common public health problems worldwide due to its rapidly increasing prevalence (2).

Allergen-specific CD4 ${ }^{+} \mathrm{T}$ cells are considered to be significantly involved in the development of asthma (3). In addition, the balance between the T-helper 1 (Th1) and Th2 cells responses are central to the pathogenesis of allergic asthma (4). Synthesis of increased levels of interleukin (IL)-4, IL- 5 and IL-13 by Th2 cells results in the production of allergen-specific immunoglobulin ( $\mathrm{Ig}) \mathrm{E}$ and the release of mediators from mast cells. By contrast, Th1 cells secrete interferon (IFN)- $\gamma$, thus suppressing Th2 immune responses. IFN- $\gamma$ is also involved in IgG2a class switching. However, in recent years, it was recognized that $\mathrm{Th} 1 / \mathrm{Th} 2$ imbalance does not entirely explain the etiology of asthma, since the reversal of Th1/Th2 imbalance does not fully control asthmatic symptoms in humans (5).

Th17 cells and regulatory $\mathrm{T}$ (Treg) cells have been previously described as two T cell population subsets that are distinct from Th1 and Th2. Th17 cells serve a crucial role in the induction of autoimmune tissue injuries and chronic inflammation through the production of various cytokines, including IL-6, IL-17 and tumor necrosis factor (TNF)- $\alpha$ (6). By contrast, Treg cells are involved in the anti-inflammatory process and maintain tolerance to self-components by producing anti-inflammatory cytokines, such as transforming growth factor (TGF)- $\beta$ and IL-10 (7). Imbalances of Th17/Treg cells have been identified in patients with allergic asthma, and were shown to be associated with moderate to severe asthma $(8,9)$. 
This suggested that the balance between Th17 and Treg cells may be important in the development of autoimmune diseases, such as asthma (5).

Gu-Ben-Fang-Xiao-Tang (GBFXT) is a mixture based on an empirical traditional Chinese medicine (TCM) formula that comprises of 11 medicinal plants (Table I). GBFXT has been used to treat bronchial asthma for 30 years at the Jiangsu Provincial Hospital of Traditional Chinese Medicine, Nanjing, China (10,11). A randomized, multicenter, parallel controlled study revealed that GBFXT combined with acupoint application had evident benefits for treating chronic asthmatic children (10). Furthermore, a previous animal study showed that GBFXT treatment was able to decrease the airway hyperresponsiveness, reduce the number of inflammation cells in the bronchoalveolar lavage fluid (BALF), and reduce the ratio of eosinophil and neutrophil granulocytes in asthma mice at the remission stage (11), implying a therapeutic effect of GBFXT on asthma. However, the precise mechanisms of GBFXT in the treatment of asthma are not fully understood. Accordingly, the present study was designed in order to determine whether GBFXT exerts an anti-inflammatory effect through the regulation of Th17/Treg balance in an ovalbumin (OVA)-induced murine asthma model.

\section{Materials and methods}

Reagents and animals. A total of 50 female BALB/c mice aged 6-8 weeks and weighing 20-22 g were purchased from Shanghai Laboratory Animal Center (Shanghai, China). The mice were maintained in a specific pathogen-free room at the Animal Facilities of Taizhou University (Taizhou, China) at $24^{\circ} \mathrm{C}$ and 55-65\% humidity, under a 12-h light/dark cycle with ad libitum access to standard chow and water. The experimental procedures were approved by the Laboratory Animal Care Committee at the Medical College of Taizhou University. All animals received care according to the Guide for the Care and Use of Laboratory Animals (National Institutes of Health, Bethesda, MD, USA). OVA and methacholine (MCH) were obtained from Sigma-Aldrich (St. Louis, MO, USA), aluminum hydroxide was purchased from Thermo Fisher Scientific, Inc. (Pierce Biotechnology; Rockford, IL, USA), and a Wright-Giemsa staining kit was purchased from Nanjing Jiancheng Bioengineering Institute (Nanjing, China).

GBFXT preparation. GBFXT was supplied by the Pharmaceutical Preparation Section of Taizhou Municipal Hospital, and was prepared according to a traditional herbal formula, as listed in Table I. In brief, the chopped herbs were combined in the listed ratios and immerged in cold water for $30 \mathrm{~min}$, then boiled twice for $30 \mathrm{~min}$. The poaching liquid was filtered and concentrated as a decoction of $2 \mathrm{~g} / \mathrm{ml}$, and stored at $4^{\circ} \mathrm{C}$ prior to administration to mice.

Experimental protocol and administration of GBFXT. A mouse asthmatic model was established as described previously (12). The sensitization, challenge and treatment schedules are shown in Fig. 1. In brief, mice (with the exception of those in the normal control group) were sensitized by intraperitoneal injection of $10 \mu \mathrm{g}$ OVA and $1 \mathrm{mg}$ aluminum hydroxide. The mice were sensitized twice, on days 0 and 7 . One week after the
Table I. Ratio of the components in Gu-Ben-Fang-Xiao-Tang.

\begin{tabular}{lc}
\hline Component & Quantity \\
\hline Radix Astragali preparata & 15 \\
Ginseng radix & 10 \\
Largehead Atractylodes rhizome & 10 \\
Glabrous greenbrier rhizome & 10 \\
Calcined oyster shells & 15 \\
Periostracum cicadae & 6 \\
Pericarpium citri reticulatae & 6 \\
Sileris radix & 3 \\
Flos magnoliae & 6 \\
Schisandra chinensis (Turcz.) bail & 6 \\
Radix Glycyrrhizae & 3 \\
Total quantity & 90
\end{tabular}

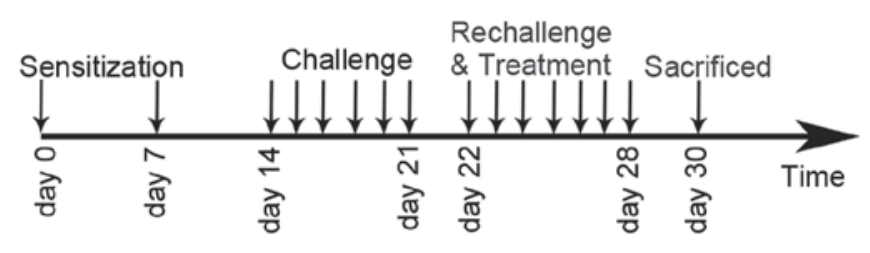

Figure 1. Sensitization, challenge and treatment schedules, as performed in the present study.

second sensitization, mice (except those in the normal control group) were anesthetized with $2 \%$ isoflurane (Sinopharm Chemical Reagent Co., Ltd., Shanghai, China) and intranasally challenged with $100 \mu \mathrm{g}$ OVA in $0.05 \mathrm{ml}$ PBS once per day between days 14 and 21. Subsequently, mice were rechallenged with $2.5 \%$ OVA-PBS between days 22 and 28 . In the GBFXT treatment groups ( $\mathrm{n}=10 /$ group), 12 or $36 \mathrm{~g} / \mathrm{kg}$ GBFXT was administered orally once daily on days 22-28. Mice in the normal control group $(n=10)$ were sensitized with PBS and were treated with PBS on days 22-28, whereas mice in the model control and in the positive control (termed montelukast group) groups ( $n=10 /$ group) were treated orally with PBS and montelukast (2.6 mg/kg; Sigma-Aldrich), respectively, once daily on days 22-28. Animals were sacrificed by overdose with pentobarbital sodium $(50 \mathrm{mg} / \mathrm{kg}) 48 \mathrm{~h}$ after the last challenge (on day 30) in order to characterize the effects of GBFXT.

Measurement of airway responsiveness. An AniRes 2005 Lung Function System (Bestlab, Beijing, China) was used to determine the airway responsiveness at $48 \mathrm{~h}$ after the last OVA challenge using the forced oscillation technique, as previously described (13). Prior to the measurement, the mice were anesthetized with intraperitoneal injection of $40 \mathrm{mg} / \mathrm{kg}$ pentobarbital sodium (Sinopharm Chemical Reagent Co., Ltd.). Subsequently, the trachea was surgically exposed and connected to a computer-controlled ventilator via an intratracheal tube. The time ratio of expiration/inspiration was pre-set at 1.5:1, while the respiratory rate was pre-set at $90 / \mathrm{min}$. Mice were stabilized for $5 \mathrm{~min}$, and then increasing concentrations of $\mathrm{MCH}$ aerosol (Sigma-Aldrich) between 
6.25 and $50 \mathrm{mg} / \mathrm{ml}$ were administered for $20 \mathrm{sec}$. Lung airway resistance (RL) values were recorded by the system following the $\mathrm{MCH}$ administration. Subsequent to each $\mathrm{MCH}$ dose, data were continuously collected for 3 min and maximum values of RL were recorded to determine changes in murine airway function.

Collection of BALF. Following sacrifice, tracheotomy was performed and $0.4 \mathrm{ml}$ cold PBS was instilled into the lung. Next, the BALF was collected by three successive aspirations (total volume, $1.2 \mathrm{ml}$ ) via tracheal cannulation. This procedure recovered $\sim 90 \%$ of the infused fluid. BALF was centrifuged at $250 \mathrm{x} \mathrm{g}$ at $4^{\circ} \mathrm{C}$ for $5 \mathrm{~min}$, and the total number of cells in BALF was counted using a hemocytometer. Subsequently, $100 \mu \mathrm{l}$ BALF was placed on a slide and centrifuged at $200 \mathrm{x} \mathrm{g}$ at $4^{\circ} \mathrm{C}$ for 10 min using a cell cytospin machine, after which the slides were dried, cells were fixed with $10 \%$ formaldehyde and stained using the Wright-Giemsa staining kit, according to the manufacturer's instructions. A total of 200 cells/slide were randomly selected to calculate the percentage of eosinophils, neutrophils, lymphocytes and macrophages in the sample under the microscope. The supernatants of BALF were collected by centrifugation at $250 \mathrm{x}$ g for $5 \mathrm{~min}$ at $4^{\circ} \mathrm{C}$ for ELISAs.

Histological assessment of lung tissue. Lung tissues were detached from the, fixed in 10\% formalin, embedded in paraffin and cut into 4- $\mu \mathrm{m}$ sections with a microtome (RM2255; Leica Biosystems, Nussloch, Germany). Next, the tissue samples were placed on glass sides and deparaffinized. The sections were then stained with hematoxylin-eosin and examined under a light microscope. The degree of cell infiltration in the airway was scored in a double-blind screen by two independent investigators. As previously described (14), the degree of perivascular and peribronchial inflammation was evaluated using scores of 0-3, as follows: 0 , little or no detectable inflammation; 1 , occasional cuffing with inflammatory cells; 2 , the majority of vessels or bronchi were surrounded by a thin layer of inflammatory cells (1-5 cells); and 3, the majority of vessels or bronchi were surrounded by a thick layer of inflammatory cells ( $>5$ cells).

Flow cytometric analysis. The spleen from each sacrificed mouse was removed, and splenocytes were prepared by gently crushing the tissues with a glass slide to release the cells. Cell preparations were filtered to remove debris and washed twice in phosphate-buffered saline (PBS), prior to resuspending in complete RPMI-1640 medium (Hyclone; GE Healthcare Life Sciences, Logan, UT, USA). For Th17-cell staining, the splenocytes were stimulated for $5 \mathrm{~h}$ with PMA $(50 \mathrm{ng} / \mathrm{ml}$; Sigma-Aldrich) and ionomycin (500 ng/ml; Sigma-Aldrich) in the presence of brefeldin A $(10 \mu \mathrm{g} / \mathrm{ml}$; Bioscience, Inc., San Diego, CA, USA). Next, the cells were harvested, washed and stained with fluorescein isothiocyanate (FITC)-conjugated rat anti-mouse CD4 (1:500; cat. no. 553046) and allophycocyanin-conjugated hamster anti-mouse CD3 (1:600; cat. no. 553066) monoclonal antibodies (BD Biosciences, San Jose, CA, USA), in the presence of FcR-Block (eBioscience, Inc., San Diego, CA, USA) at $4^{\circ} \mathrm{C}$ for $30 \mathrm{~min}$. After washing with PBS, cells were fixed using CytoFix/CytoPerm buffer (BD Biosciences), according to the manufacturer's instructions, and

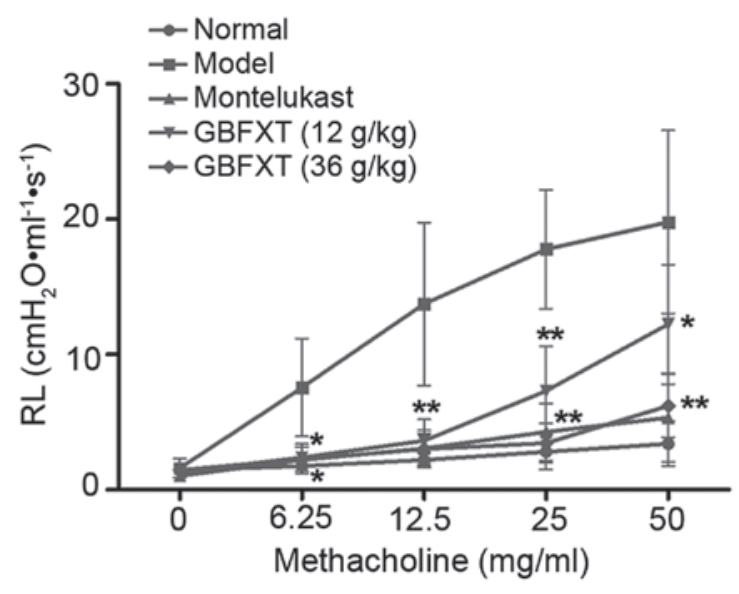

Figure 2. Effect of GBFXT on airway hyperresponsiveness in response to methacholine. Values represent the means \pm standard deviation of 10 mice. ${ }^{*} \mathrm{P}<0.05,{ }^{* *} \mathrm{P}<0.01$ vs. the model group. GBFXT, Gu-Ben-Fang-Xiao-Tang; $\mathrm{RL}$, lung airway resistance.

stained with phycoerythrin (PE)-conjugated rat anti-mouse IL-17A monoclonal antibody (1:300; cat. no. 559502; BD Biosciences) at $4^{\circ} \mathrm{C}$ for $30 \mathrm{~min}$. For Treg-cell staining, the splenocytes were initially stained with FITC-conjugated rat anti-mouse CD4 (1:400; cat. no. 11-0042-81; eBioscience, Inc.) and PE-conjugated rat anti-mouse CD25 (1:800; cat. no. 12-0251-81) monoclonal antibodies (eBioscience, Inc.) at $4^{\circ} \mathrm{C}$ for $30 \mathrm{~min}$. Intracellular staining for FoxP3 was performed by using a FoxP3 staining kit (eBioscience, Inc.). Isotype controls were treated to enable correct compensation and to confirm antibody specificity. Data were acquired on a FACS Calibur flow cytometer (BD Bioscience) and analyzed using FlowJo software, version 7.6 (FlowJo LLC, Ashland, OR, USA).

ELISA. BALF cell-free supernatants $(50 \mu \mathrm{l})$ were collected by centrifugation at $250 \mathrm{x} \mathrm{g}$ for $5 \mathrm{~min}$ at $4^{\circ} \mathrm{C}$. The concentrations of IL-17A and IL-10 in the BALF were measured using ELISA kits (cat. nos. 88-7371-22 and 88-7105-22, respectively; eBioscience, Inc.), according to the manufacturer's instructions. All assays were performed in triplicate. The concentration of each protein was calculated from the standard curve.

Statistical analysis. Data were analyzed using a two-tailed Student's t-test and the Graphpad Prism version 5 software (GraphPad Software, Inc., La Jolla, CA, USA). The results are expressed as the mean \pm standard deviation, and differences with a $\mathrm{P}<0.05$ were regarded as statistically significant.

\section{Results}

Effect of GBFXT on airway hyperresponsiveness. Fig. 2 shows the airway hyperresponsiveness, as recorded during $\mathrm{MCH}$-induced constriction. The results indicated that the RL value of the OVA-challenged group (model group) was significantly higher compared with that of the normal group $(\mathrm{P}<0.05)$ when using concentrations of $6.25-50 \mathrm{mg} / \mathrm{ml} \mathrm{MCH}$. However, mice sensitized and challenged with OVA, followed by treatment with different doses of GBFXT, exhibited a 
Table II. Total cell number and cellular composition in BALF of mice.

\begin{tabular}{lccccc}
\hline Group & Total cells $\left(\times 10^{4} / \mathrm{ml}\right)$ & Eosinophils $(\%)$ & Neutrophils $(\%)$ & Lymphocytes $(\%)$ & Macrophages (\%) \\
\hline Normal & $71.3 \pm 12.3$ & $0.81 \pm 0.7$ & $21.1 \pm 7.4$ & $50.4 \pm 14.7$ & $26.3 \pm 5.7$ \\
Model & $135.0 \pm 30.7$ & $4.5 \pm 1.7$ & $31.8 \pm 6.7$ & $30.4 \pm 4.1$ & $34.2 \pm 5.1$ \\
Montelukast & $86.2 \pm 24.8^{\mathrm{a}}$ & $1.37 \pm 0.9^{\mathrm{b}}$ & $27.8 \pm 5.4$ & $33.4 \pm 8.3$ & $36.4 \pm 6.1$ \\
GBFXT (12 g/kg) & $95.1 \pm 23.1^{\mathrm{a}}$ & $3.4 \pm 1.4$ & $24.2 \pm 5.1^{\mathrm{b}}$ & $32.5 \pm 6.8$ & $36.9 \pm 6.8$ \\
GBFXT (36 g/kg) & $84.4 \pm 21.3^{\mathrm{a}}$ & $1.9 \pm 0.8^{\mathrm{a}}$ & $22.7 \pm 4.3^{\mathrm{b}}$ & $31.9 \pm 7.2$ & $38.1 \pm 7.3$ \\
\hline
\end{tabular}

Values are presented as the mean \pm standard deviation of 10 mice. ${ }^{\mathrm{a}} \mathrm{P}<0.05$ and ${ }^{\mathrm{b}} \mathrm{P}<0.01$, vs. the model group. GBFXT, Gu-Ben-Fang-Xiao-Tang; BAFL, bronchoalveolar lavage fluid.

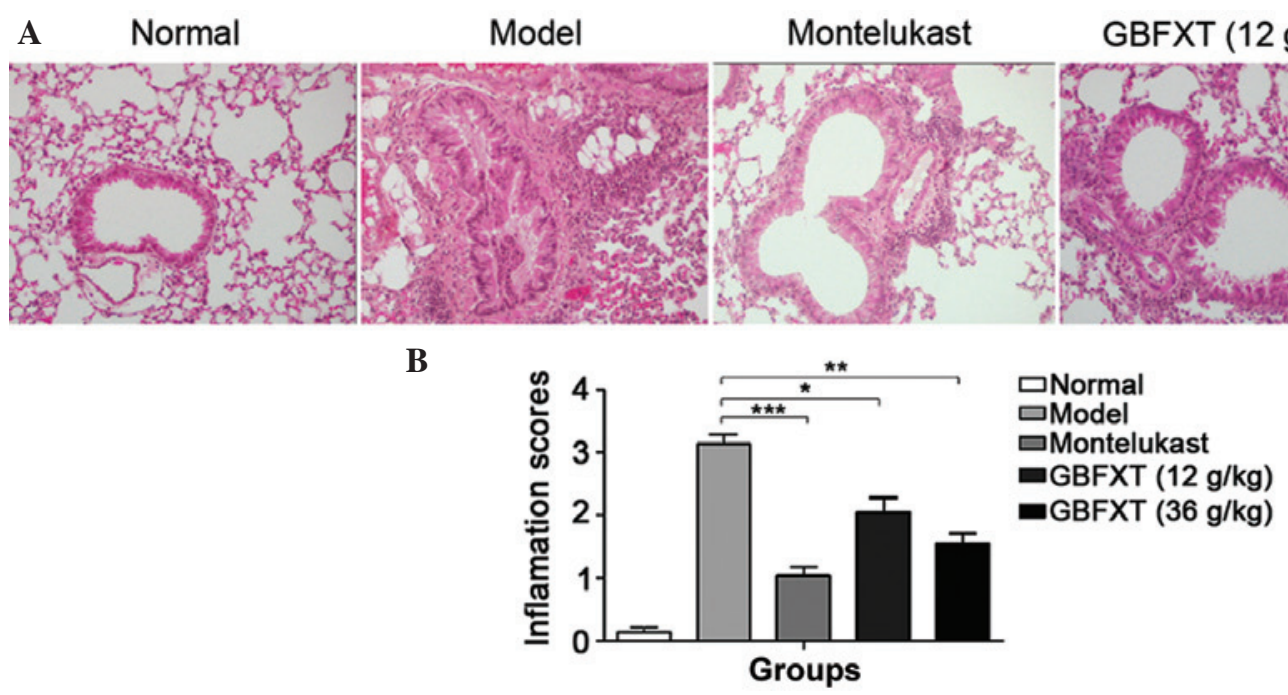

Figure 3. Effect of GBFXT on inflammatory cell infiltration in the lung tissue of mice. (A) Representative hematoxylin-eosin stained lung sections (magnification, $\mathrm{x} 200$ ); and (B) inflammation scores in the various groups. Total lung inflammation was defined as the mean of the peribronchial and perivascular inflammation scores. Values represent the mean \pm standard deviation of 10 mice. ${ }^{*} \mathrm{P}<0.05,{ }^{* *} \mathrm{P}<0.01$ and ${ }^{* * * *} \mathrm{P}<0.001$ vs. model group. GBFXT, Gu-Ben-Fang-Xiao-Tang.

reduced mean $\mathrm{RL}$ values upon exposure to $6.25-50 \mathrm{mg} / \mathrm{ml}$ $\mathrm{MCH}$ when compared with the RJ values in the model group. In addition, positive control mice administered montelukast ( $2.6 \mathrm{mg} / \mathrm{kg}$ ) showed markedly decreased RL values compared with the model group, which were similar to the values achieved using GBFXT $(\mathrm{P}<0.05)$. These results suggest that GBFXT suppresses airway hyperresponsiveness during $\mathrm{MCH}$-induced constriction.

Effect of GBFXT on OVA-induced eosinophilia in BALF. Alterations in the total cell levels in the BALF were then investigated in order to determine the effect of GBFXT treatment on asthma. Suppression of eosinophilia following GBFXT treatment in OVA-challenged mice was estimated by counting the percentage of eosinophils and other cells present in the BALF at $48 \mathrm{~h}$ after the last challenge. As shown in Table II, OVA induced a marked influx of leukocyte and eosinophil levels in the BALF in OVA-challenged mice. By contrast, OVA-sensitized and -challenged mice treated with GBFXT displayed a significantly reduced proportion of leukocytes $(\mathrm{P}<0.05)$ and eosinophils $(\mathrm{P}<0.05)$, while a significant decrease in absolute neutrophils was observed compared with the model group upon asthma induction $(\mathrm{P}<0.01)$. These results suggest that GBFXT reduces the percentage of leukocytes and

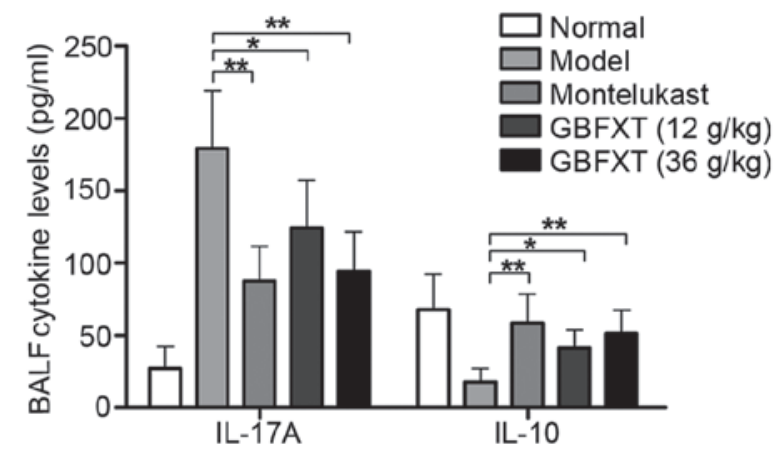

Figure 4. Effect of GBFXT on cytokine levels in BALF. Values represent the means \pm standard deviation of 10 mice. ${ }^{*} \mathrm{P}<0.05$ and ${ }^{* *} \mathrm{P}<0.01$ vs. model group. GBFXT, Gu-Ben-Fang-Xiao-Tang; BAFL, bronchoalveolar lavage fluid; IL, interleukin.

eosinophils, and decreases absolute neutrophil infiltration, in BALF.

Effect of GBFXT on OVA-induced eosinophilia in lung tissue. As shown in Fig. 3, a significant infiltration of inflammatory cells into the peribronchial and perivascular connective tissues was observed in OVA-induced asthmatic lung tissues when 

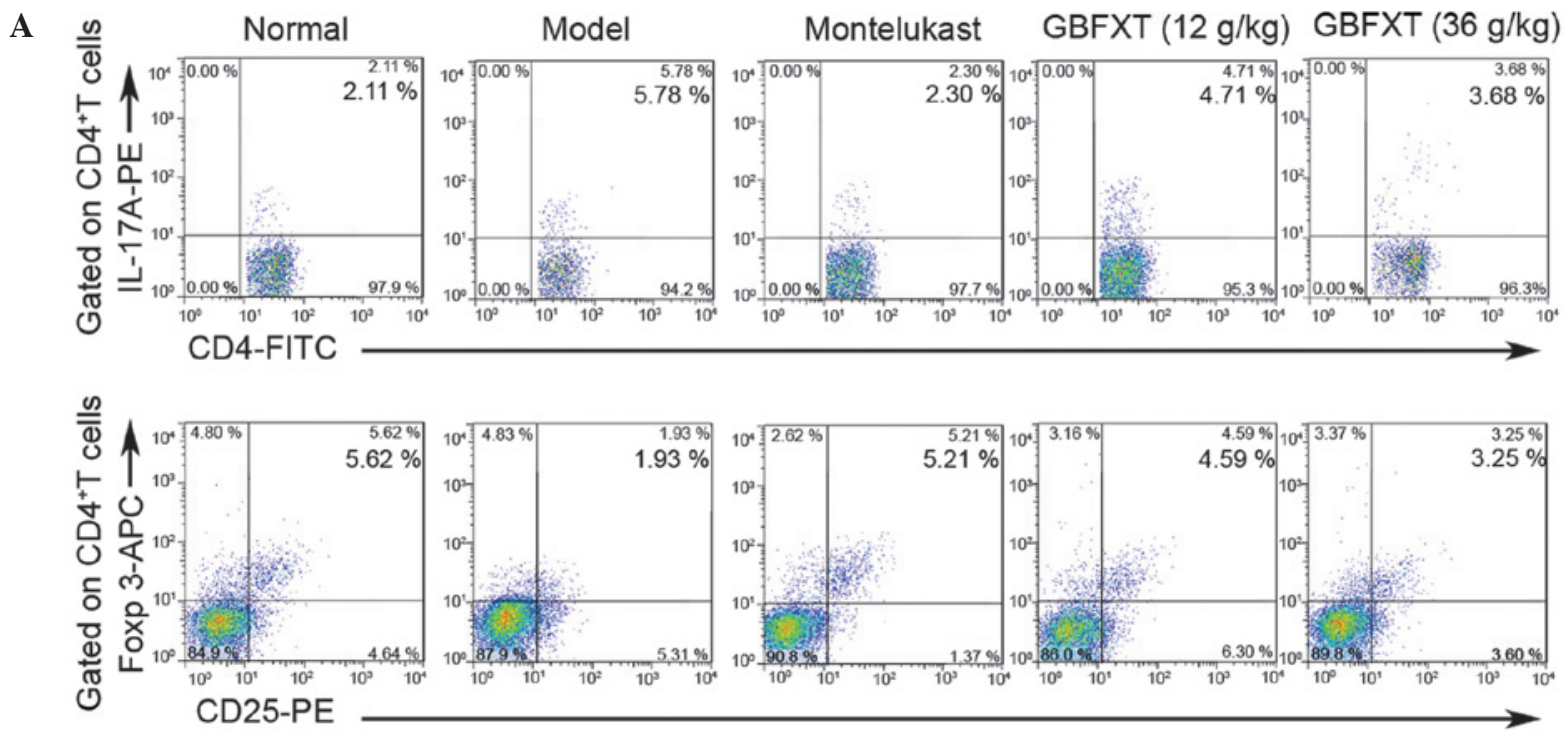

B
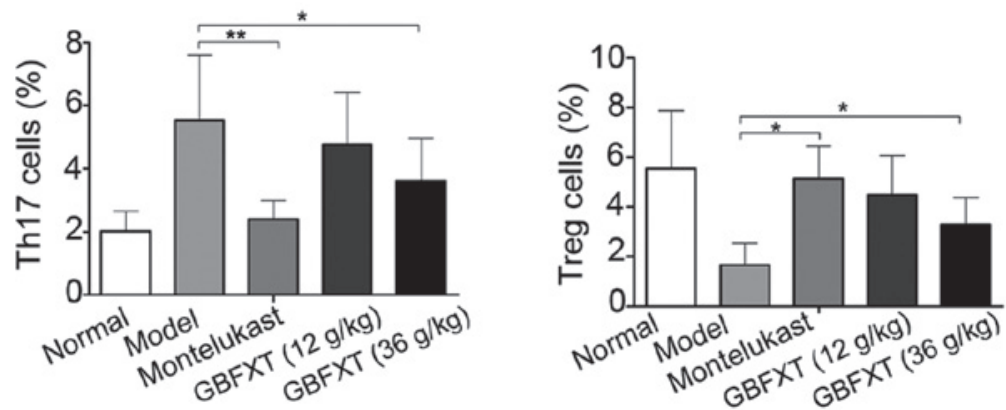

Figure 5. Effect of GBFXT on Th17 and Treg cells. (A) Representative FACS flow cytometry profiles; and (B) percentages of Th17 cells and Treg cells in various groups. One representative of 10 mice in each group is shown in the FACS profiles. Values represent the mean \pm standard deviation of 10 mice. ${ }^{*} \mathrm{P}<0.05$ and ${ }^{* *} \mathrm{P}<0.01$, vs. model group. GBFXT, Gu-Ben-Fang-Xiao-Tang; FACS, fluorescence-activated cell sorting; IL, interleukin; PE, phycoerythrin; FITC, fluorescein isothiocyanate; Foxp 3, forkhead box P3; APC, allophycocyanin; Th17, T helper 17; Treg, regulatory T.

compared with the normal lung tissue $(\mathrm{P}<0.01)$. Furthermore, the majority of leukocytes present were eosinophils. The normal group presented no alteration in the extent of inflammatory cell infiltration, and similar findings were observed in the montelukast-treated positive control mice. However, eosinophilia in OVA-sensitized and -challenged mice treated with GBFXT was significantly attenuated compared with the level of eosinophils observed in OVA-challenged mice, as shown in Fig. $3(\mathrm{P}<0.05$ and $\mathrm{P}<0.01$, respectively). These results suggest that GBFXT inhibits inflammatory cell recruitment to lung tissues.

Effect of GBFXT on cytokine levels in BALF. As shown in Fig. 4, OVA challenging triggered a significant increase in IL-17A expression levels in the BALF, compared with the levels in normal fluid $(\mathrm{P}<0.01)$. In OVA-sensitized and -challenged mice treated with GBFXT, the increase in IL-17A cytokine levels was significantly suppressed $(\mathrm{P}<0.05$ and $\mathrm{P}<0.01$, respectively), when compared with the levels observed in the asthmatic model group. Regarding IL-10 expression, OVA challenging resulted in a significant reduction in the cytokine levels in the BALF $(\mathrm{P}<0.01)$, when compared with the levels in normal fluid. IL-10 cytokine levels were significantly enhanced in mice with OVA-induced asthma that were treated with GBFXT $(\mathrm{P}<0.05)$, when compared with the concentration detected in the model group. These results suggest that
GBFXT treatment significantly decreases the IL-17A cytokine levels and increases the IL-10 cytokine levels in the BALF.

Effect of GBFXT on Th17 and Treg cells. In the present study, flow cytometric analysis was used to determine the effect of GBFXT on the proportion of Th17 and Treg cells. As shown in Fig. 5, the percentage of Th17 cells in the model group $(5.54 \pm 2.04 \%)$ was significantly higher compared with that in the normal group $(2.01 \pm 0.64 \% ; \mathrm{P}<0.01)$. In addition, the proportion of Th17 cells was significantly lower in the montelukast $(2.14 \pm 0.57 \% ; \mathrm{P}<0.01)$ and $36 \mathrm{~g} / \mathrm{kg}$ GBFXT $(3.61 \pm 1.34 \%$; $\mathrm{P}<0.05)$ treatment groups compared with those in the model group. Furthermore, the proportion of Treg cells in the model group $(1.67 \pm 0.87 \%)$ was significantly lower compared with that in the normal group $(5.54 \pm 2.34 \%$; $\mathrm{P}<0.01)$, while it was significantly higher in the montelukast $(5.14 \pm 1.31 \%$; $\mathrm{P}<0.05)$ and $36 \mathrm{~g} / \mathrm{kg}$ GBFXT $(3.29 \pm 1.07 \%$; $\mathrm{P}<0.05)$ treatment groups, when compared with those in the model group. These results suggest that GBFXT significantly suppresses Th17 and increases Treg cell proportions in asthmatic mice.

\section{Discussion}

In the present study, the immunoregulatory effects and possible mechanism of GBFXT were investigated in a OVA-induced 
chronic allergic asthma murine model. The results showed that GBFXT treatment suppressed the airway hyperresponsiveness and eosinophil granulocyte infiltration, while it significantly decreased IL-17A and increased IL-10 cytokine levels. Furthermore, GBFXT treatment significantly suppressed the proportion of Th17 cells and increased the proportion of Tregs in asthmatic mice. Therefore, to the best of our knowledge, the present study demonstrated for the first time that GBFXT treatment may attenuate the airway inflammation in an asthma animal model by regulating the Th17/Treg balance.

Allergic disorders, such as asthma, represent a severe public health problem in children. The chronic nature of these diseases and the fear of known side effects of synthetic drugs result in numerous families seeking complementary and alternative medicine (CAM) (15). The use of TCM is a major component of the CAM modality, and TCM formulas have been used for centuries for the treatment of asthma, with a number of successful cases previously reported $(12,16,17)$. GBFXT, a formula designed following the TCM theories and clinical experience, has been used to treat asthmatic patients in China for three decades (10). Unlike the side effect occurring when using corticosteroids, GBFXT relieves asthmatic syndrome without total immune suppression, and also has an increased heightening effect to the immune function of mice (18). In support of the present study findings, a preclinical study performed by Yuan et al (11) reported that GBFXT treatment was able to decrease airway hyperresponsiveness, reduce BALF inflammation cell count, and the ratio of eosinophil and neutrophil granulocytes. In addition, GBFXT resulted in an increase was observed in the IFN- $\gamma$ level in the BALF and relieved the infiltration of inflammatory cells in the airway in asthmatic mice at the remission stage (11), implying a therapeutic effect of GBFXT on asthma.

Previous clinical studies have demonstrated that the proportion of Th17 cells in the BALF, sputum and lung tissue, as well as the serum levels of IL-17, in asthma patients were significantly increased compared with those in normal control patients, and were positively associated with the severity of asthma symptoms $(8,19-21)$. In addition, certain studies using animal asthma models have also shown that Th17 cells and their cytokines, including IL-17A and IL-17F, are involved in antigen-induced neutrophil recruitment, as well as in the enhancement of Th2 cell-mediated eosinophil recruitment into the airways $(22,23)$. In human allergy patients, Treg cell numbers decrease in the peripheral blood and BALF, and cannot suppress the cell proliferation and cytokine production of allergen-stimulated $\mathrm{CD}^{+}{ }^{+} \mathrm{T}$ cells (24-26). Furthermore, several murine studies have demonstrated that the induction of Treg cell function reverses the airway hyperresponsiveness and protects against experimentally-induced asthma $(27,28)$. In the current study, the results of flow cytometric analysis revealed that OVA challenge was able to significant increase the proportion of Th17 cells and decrease the proportion of Treg cells, resulting in imbalance of the Th17/Treg cell ratio; this suggests that the Th17/Treg imbalance serves an important role in the pathogenesis of asthma. Finally, administration of GBFXT significantly suppressed Th17 cells and increased Treg cells in mice with OVA-induced asthma, and attenuate the airway inflammation.

In conclusion, the present study demonstrated a novel mechanism of GBFXT in the treatment of asthma. The current findings suggest that GBFXT may effectively inhibit the progression of airway inflammation in allergic asthma. The anti-inflammatory effects of GBFXT may be mediated partially by modulation of the Th17/Treg balance.

\section{Acknowledgements}

The current study was supported by grants from the Administration of Traditional Chinese Medicine of Zhejiang Province (nos. 2012ZB174 and 2013ZA134) and the Science and Technology Planning Project of Taizhou City (no. 1201KY21).

\section{References}

1. Bice JB, Leechawengwongs E and Montanaro A: Biologic targeted therapy in allergic asthma. Ann Allergy Asthma Immunol 112: 108-115, 2014.

2. Pawankar R: Allergic diseases and asthma: A global public health concern and a call to action. World Allergy Organ J 7: 12, 2014.

3. Pascual RM and Peters SP: Airway remodeling contributes to the progressive loss of lung function in asthma: An overview. J Allergy Clin Immunol 116: 477-486; quiz 487, 2005.

4. Umetsu DT and DeKruyff RH: Th1 and Th2 CD4 ${ }^{+}$cells in the pathogenesis of allergic diseases. Proc Soc Exp Biol Med 215: 11-20, 1997.

5. Schmidt-Weber CB: Th17 and treg cells innovate the TH1/TH2 concept and allergy research. Chem Immunol Allergy 94: 1-7, 2008.

6. Oboki K, Ohno T, Saito H and Nakae S: Th17 and allergy. Allergol Int 57: 121-134, 2008.

7. Choi IS: Immune tolerance by induced regulatory $\mathrm{T}$ cells in asthma. Allergy Asthma Immunol Res 4: 113-115, 2012.

8. Shi YH, Shi GC, Wan HY, Jiang LH, Ai XY, Zhu HX, Tang W, Ma JY, Jin XY and Zhang BY: Coexistence of Th1/Th2 and Th17/Treg imbalances in patients with allergic asthma. Chin Med J (Engl) 124: 1951-1956, 2011.

9. Toldi G, Molvarec A, Stenczer B, Müller V, Eszes N, Bohács A, Bikov A, Rigó J Jr, Vásárhelyi B, Losonczy G and Tamási L: Peripheral T(h)1/T(h)2/T(h)17/regulatory T-cell balance in asthmatic pregnancy. Int Immunol 23: 669-677, 2011.

10. Yuan XJ, Sun YQ, Wang SM, Li YN, Wang MQ and Liu XR: Clinical research of Gubenfangxiao decoction combined with point application on chronic asthmatic children in 100 cases. Zhong Hua Zhong Yi Yao Za Zhi 21: 2306-2309, 2010 (In Chinese).

11. Yuan X, Xia C and Wang S: Therapeutic effects of Guben Fangxiao Decoction on asthma mice at remission stage. Zhong Yao Xin Yao Yu Lin Chuang Yao Li Bian Ji Bu 3: 257-260, 2010 (In Chinese).

12. Lee MY, Shin IS, Lim HS and Shin HK: A water extract of Samchulkunbi-tang attenuates airway inflammation by inhibiting inos and MMP-9 activities in an ovalbumin-induced murine asthma model. BMC Complement Altern Med 12: 257, 2012.

13. Du Q, Chen Z, Zhou LF, Zhang Q, Huang M and Yin KS: Inhibitory effects of astragaloside IV on ovalbumin-induced chronic experimental asthma. Can J Physiol Pharmacol 86: 449-457, 2008.

14. Tournoy KG, Kips JC, Schou C and Pauwels RA: Airway eosinophilia is not a requirement for allergen-induced airway hyperresponsiveness. Clin Exp Allergy 30: 79-85, 2000.

15. Li XM: Complementary and alternative medicine in pediatric allergic disorders. Curr Opin Allergy Clin Immunol 9: 161-167, 2009.

16. Wen MC, Wei CH, Hu ZQ, Srivastava K, Ko J, Xi ST, Mu DZ, Du JB, Li GH and Wallenstein S: Efficacy and tolerability of anti-asthma herbal medicine intervention in adult patients with moderate-severe allergic asthma. J Allergy Clin Immunol 116: 517-524, 2005.

17. Lin CH, Yeh CH, Lin LJ, Wang JS, Wang SD and Kao ST: The Chinese herbal medicine formula Sheng-Fei-Yu-Chuan-Tang suppresses Th2 responses and increases IFN $\gamma$ in Dermatophagoides pteronyssinus induced chronic asthmatic mice. Evid Based Complement Alternat Med 2013: 984121, 2013.

18. Cao S, Yuan X and Sun Y: Effects of Guben Fangxiao Yin on immune function in mice. J Liaoning Univ Trad Chinese Med 5: $16,2013$.

19. Albano GD, Di Sano C, Bonanno A, Riccobono L, Gagliardo R, Chanez P, Gjomarkaj M, Montalbano AM, Anzalone G, La Grutta S and Profita M: Th17 immunity in children with allergic asthma and rhinitis: UA pharmacological approach. PLoS One 8: e58892, 2013. 
20. Chien JW, Lin CY, Yang KD, Lin CH, Kao JK and Tsai YG: Increased IL-17A secreting CD4 ${ }^{+} \mathrm{T}$ cells, serum IL-17 levels and exhaled nitric oxide are correlated with childhood asthma severity. Clin Exp Allergy 43: 1018-1026, 2013.

21. Silverpil E and Lindén A: IL-17 in human asthma. Expert Rev Respir Med 6: 173-186, 2012.

22. Wakashin H, Hirose K, Maezawa Y, Kagami S, Suto A, Watanabe N, Saito Y, Hatano M, Tokuhisa T, Iwakura Y, et al: IL-23 and Th17 cells enhance Th2-cell-mediated eosinophilic airway inflammation in mice. Am J Respir Crit Care Med 178: 1023-1032, 2008.

23. Cao Y, Feng X, Wang Y, Zhao L and Han T: An increased of Th17 cells and IL-23 and IL-17 in the lymph and blood of rats with bronchial asthma. Xi Bao Yu Fen Zi Mian Yi Xue Za Zhi 29: 1281-1284, 2013 (In Chinese).

24. Hartl D, Koller B, Mehlhorn AT, Reinhardt D, Nicolai T, Schendel DJ, Griese M and Krauss-Etschmann S: Quantitative and functional impairment of pulmonary $\mathrm{CD} 4{ }^{+} \mathrm{CD} 25 \mathrm{hi}$ regulatory T cells in pediatric asthma. J Allergy Clin Immunol 119: $1258-1266,2007$.
25. Ling EM, Smith T, Nguyen XD, Pridgeon C, Dallman M, Arbery J, Carr VA and Robinson DS: Relation of CD4 ${ }^{+} \mathrm{CD} 25^{+}$ regulatory T-cell suppression of allergen-driven T-cell activation to atopic status and expression of allergic disease. Lancet 363: 608-615, 2004.

26. Strickland DH, Stumbles PA, Zosky GR, Subrata LS Thomas JA, Turner DJ, Sly PD and Holt PG: Reversal of airway hyperresponsiveness by induction of airway mucosal $\mathrm{CD} 4^{+} \mathrm{CD} 25^{+}$regulatory $\mathrm{T}$ cells. J Exp Med 203: 2649-2660, 2006.

27. Lewkowich IP, Herman NS, Schleifer KW, Dance MP, Chen BL, Dienger KM, Sproles AA, Shah JS, Köhl J, Belkaid Y and Wills-Karp M: $\mathrm{CD} 4{ }^{+} \mathrm{CD} 25^{+} \mathrm{T}$ cells protect against experimentally induced asthma and alter pulmonary dendritic cell phenotype and function. J Exp Med 202: 1549-1561, 2005.

28. Park BS, Hong GU and Ro JY: Foxp3(+)-Treg cells enhanced by repeated low-dose gamma-irradiation attenuate ovalbumin-induced allergic asthma in mice. Radiat Res 179: 570-583, 2013. 